\title{
Involvement of Intramolecular Interactions in the Regulation of G Protein-Coupled Receptor Kinase 2
}

\author{
SUSANA SARNAGO, RAMÓN ROCA, ANTONIO DE BLASI, ALFONSO VALENCIA, FEDERICO MAYOR, JR., and \\ CRISTINA MURGA \\ Centro de Biología Molecular "Severo Ochoa" (S.S., F.M., C.M.) and Centro Nacional de Biotecnología (R.R., A.V.), Consejo Superior de \\ Investigaciones Científicas-Universidad Autónoma de Madrid, Madrid, Spain; and INM Neuromed, Pozzilli, Italy (A.d.B.)
}

Received March 3, 2003; accepted May 20, 2003

This article is available online at http://molpharm.aspetjournals.org

\begin{abstract}
The G protein-coupled receptor (GPCR) kinase GRK2 phosphorylates $\mathrm{G}$ protein-coupled receptors in an agonist-dependent manner. GRK2 activity is modulated through interactions of diverse domains of the kinase with $G$ protein $\beta \gamma$ subunits, several lipids, anchoring proteins, and activated receptors. We report that kinase activity toward either GPCR (rhodopsin) or a synthetic peptide substrate is enhanced in the presence of GST-GRK2 fusion proteins or peptides corresponding to either $\mathrm{N}$ - or C-terminal sequences of GRK2. This direct stimulatory action of intrinsic domains on GRK2 activity does not add to the effect of other regulators, such as $\mathrm{G} \beta \gamma$ subunits, and strongly suggests the existence of some mode of autoregulation. The existence of regulatory intramolecular interactions in GRK2 is
\end{abstract}

supported by the facts that a C-terminal peptide protects the $\mathrm{N}$-terminal region from proteolytic cleavage and that two domains of GRK2 independently coexpressed in cells associate as assessed by immunoprecipitation. Molecular modeling suggests that intramolecular interactions among the N-terminal, C-terminal and kinase domains would keep GRK2 in a constrained conformation characteristic of an inactive, basal state. Our model proposes that disruption of such intramolecular contacts by intermolecular interactions with regulatory proteins (mimicked by exogenously added kinase fragments in vitro) would promote the conformational changes required to bring about GRK2 translocation and activation.
G protein-coupled receptors (GPCR) are known to be phosphorylated in an agonist-dependent manner by G proteincoupled receptor kinases (GRKs), leading to the functional uncoupling of the receptor and subsequent loss of responsiveness, a process termed desensitization (Pierce et al., 2002). The GRK family consists of seven known subtypes that share a number of structural and functional similarities (Pitcher et al., 1998; Penn et al., 2000). The structural architecture of the GRKs includes a centrally located catalytic domain flanked by an amino-terminal domain of 183 to 188 amino acids that includes a region of homology to regulators of G protein signaling (RGS) proteins (Sallese et al., 2000), and a carboxyl terminus of variable length that contains either sites of post-translational modifications or domains that may engage in regulatory and targeting interactions (Pitcher et al., 1998; Penn et al., 2000). The mechanisms that govern the localization and activity of GRKs have been extensively studied from a cellular point of view, whereas they remain largely undefined at a molecular level.

This research was supported by Ministerio de Ciencia y Tecnología grants PM98-0020 and SAF 2002-0408 and by Fundación Ramón Areces.

The supplemental material cited in the text is available at http://molpharm. aspetjournals.org/cgi/content/full/64/3/DC1.
The GRK2 isoform is ubiquitously expressed and is able to phosphorylate a variety of activated GPCRs (Pitcher et al., 1998). GRK2 activity and subcellular localization seems to be subject to complex regulatory processes. First, GRK2 exhibits stimulus-dependent translocation to the periphery of the plasma membrane that is mediated by the carboxyl-terminal portion of the kinase (Pitcher et al., 1992). It contains a G protein $\beta \gamma$ subunit $(\mathrm{G} \beta \gamma$ )-binding region (residues 546-670) partially overlapping with a Pleckstrin homology $(\mathrm{PH})$ domain (residues 553-651) that also mediates interactions with phosphatidylinositol 4,5-bisphosphate $\left(\mathrm{PIP}_{2}\right)$ and other phospholipids. The stretch encompassing residues 643 to 673 of GRK2 seems to be critical for $\mathrm{G} \beta \gamma$ binding, and a synthetic peptide corresponding to this sequence has been reported to impair G $\beta \gamma$ /GRK2 interaction (Koch et al., 1993). Binding of G $\beta \gamma$ and lipids to the C-terminal domain of GRK2 synergistically enhances agonist-dependent receptor phosphorylation, and both ligands are required for effective membrane localization of the kinase (Pitcher et al., 1995; DebBurman et al., 1996; Pitcher et al., 1996). In contrast, the interaction of the N-terminal GRK2 domain with an anchoring protein in internal microsomal membranes leads to inhibition of the bound kinase (Murga et al., 1996).

ABBREVIATIONS: GPCR, G protein-coupled receptor; GRK, G protein-coupled receptor kinase; RGS, regulators of G protein signaling; PH, Pleckstrin homology; $\mathrm{PIP}_{2}$, phosphatidylinositol 4,5-bisphosphate; HEK, human embryonic kidney; PAK1, p21 activated kinase 1; GST, glutathione S-transferase. 
GRK2 activity is also modulated by interactions with the agonist-occupied form of GPCR that serve both as substrates and activators of GRKs (Chen et al., 1993). Accordingly, synthetic peptides derived from intracellular loops of GPCRs or the wasp peptide mastoparan have been shown to regulate GRK2 activity (Benovic et al., 1990; Haga et al., 1994). New interactions leading to positive or negative regulation of different GRKs have been reported to occur with caveolin, calmodulin, actin, tubulin (see Penn et al., 2000, for a review), and phosphatidylinositol 3'-OH kinase (Naga Prasad et al., 2001). Thus, GRK2 seems to emerge as a multidomain protein capable of associating with many different modulators.

In sum, the control of GRK2 activity and subcellular localization seems to involve the interaction of both $\mathrm{N}$ - and $\mathrm{C}$ terminal domains of the kinase with different intracellular targets. However, the biochemical mechanisms that may explain the relatively low kinase activity displayed by GRK2 in the absence of stimulators and how all the possible kinase regulators bring about rapid GRK2 activation and membrane translocation have not been elucidated at a molecular level. Here, we provide evidence for the involvement of intramolecular interactions in regulating GRK2 conformation and activity. We report that fusion proteins and synthetic peptides encoding several domains of the kinase are able to modulate GRK2 activity toward different substrates. Based on the protective effect of a C-terminal peptide of GRK2 on the $\mathrm{N}$-terminal cleavage of the kinase by trypsin, the coprecipitation of $\mathrm{N}$ - and C-terminal domains of GRK2 and molecular modeling data, we propose a model for the regulation of kinase activity by internal and external modulators.

\section{Materials and Methods}

Materials. Bovine GRK2 was overexpressed and purified from baculovirus-infected Sf9 cells as described previously (Murga et al., 1996). Recombinant baculovirus for GRK2 and purified G $\beta \gamma$ subunits from bovine brain were kindly provided by Dr. J. Benovic (Kimmel Cancer Center, Thomas Jefferson University, Philadelphia, PA). The peptide $643-673$ comprising the $\beta \gamma$-binding domain of bovine GRK2 and the corresponding scrambled peptide were kindly provided by Dr. M. E. Patarroyo. The peptide substrate (RRREEEEESAAA) was synthesized with a 431A peptide synthesizer (Applied Biosystems, Foster City, CA). The unrelated peptide (EEISEVKMDAEFRMDSGYC) used in control experiments of proteolysis with trypsin was synthesized by Bio-Synthesis, Inc. (Lewisville, TX). TPCK-Trypsin attached to beaded agarose was obtained from Sigma (St. Louis, MO). $\left[\gamma_{-}{ }^{32} \mathrm{P}\right] \mathrm{ATP}$ was purchased from Amersham Biosciences (Piscataway, NJ) All other reagents were of the highest grade commercially available.

Generation and Purification of GST-GRK2 Fusion Proteins. Fusion proteins containing amino acids 50 to 145 (FP1) and 437 to 689 (FP2) of GRK2 were generated essentially as reported previously (Murga et al., 1996). The fusion proteins were purified, and a functional characterization was also performed as described by assessing the binding of the GRK2 purified fragments to different protein partners (Murga et al., 1996).

Determination of GRK2 Activity toward Rhodopsin. GRK2 activity was determined by using purified urea-treated rod outer segments as substrates (Murga et al., 1996). Recombinant bovine GRK2 (10 nM) was preincubated in $20 \mathrm{mM}$ Tris-HCl, pH 7.5, $1 \mathrm{mM}$ $\mathrm{MgCl}_{2}$ for $15 \mathrm{~min}$ at $37^{\circ} \mathrm{C}$, alone or in the presence of fusion proteins or of a peptide corresponding to the $\beta \gamma$-binding domain of bovine GRK2 (residues 643-673, $5 \mu \mathrm{M}$ ). The phosphorylation reaction (30 min at $30^{\circ} \mathrm{C}$ in a final volume of $50 \mu \mathrm{l}$ ) was initiated by the sequential addition of phosphorylation buffer and purified rhodopsin prepara- tion to the following final concentrations: $27 \mathrm{mM}$ Tris, $\mathrm{pH} 7.5,1.4$ mM EDTA, $1 \mathrm{mM}$ EGTA, $5.5 \mathrm{mM} \mathrm{MgCl} 2$, $4.5 \mathrm{mM} \mathrm{NaF}, 57 \mu \mathrm{M}\left[\gamma_{-}{ }^{32} \mathrm{P}\right]$ ATP (2-3 cpm/fmol), and $0.5 \mu \mathrm{M}$ rhodopsin. Phosphorylated rhodopsin was resolved by electrophoresis and quantified by autoradiography.

Determination of GRK2 Activity toward Casein and a Peptide Substrate. Phosphorylation of casein $(28.6 \mu \mathrm{M})$ was performed in a final volume of $30 \mu \mathrm{l}$ containing $20 \mathrm{mM}$ Tris- $\mathrm{HCl}, \mathrm{pH} 7.5,2 \mathrm{mM}$ EDTA, $3.7 \mathrm{mM} \mathrm{MgCl} 2,4.5 \mathrm{mM} \mathrm{NaF}, 0.1 \mathrm{mM}\left[\gamma_{-}{ }^{32} \mathrm{P}\right] \mathrm{ATP}(4800$ $12000 \mathrm{cpm} / \mathrm{pmol})$ and GRK2 (25 nM) as described previously (DebBurman et al., 1996). Reactions were stopped by addition of $30 \mu \mathrm{l}$ of SDS-PAGE sample buffer and phosphorylated casein was resolved by electrophoresis followed by autoradiography. GRK2 activity was quantified in a peptide phosphorylation assay using the peptide RRREEEEESAAA as the substrate essentially as described previously (Onorato et al., 1995).

Proteolytic Digestion of GRK2 by Trypsin and Determination of N-Terminal Cleavage Sites. Recombinant GRK2 $(4 \mu \mathrm{g})$ was preincubated for $10 \mathrm{~min}$ at $37^{\circ} \mathrm{C}$ in the presence or absence of the GRK2 643-673 peptide $(25-100 \mu \mathrm{M})$ or other peptides as controls, and treated with TPCK-trypsin ( 0.4 units) for 5 to $30 \mathrm{~min}$ at $25^{\circ} \mathrm{C}$ in $20 \mathrm{mM}$ Tris, $\mathrm{pH} 8.0$, and $1 \mathrm{mM} \mathrm{MgCl}{ }_{2}$ in a final volume of $20 \mu \mathrm{l}$. After centrifugation for $1 \mathrm{~min}$ at $14,000 \mathrm{rpm}$, the reaction was stopped by mixing the supernatant with $10 \mu \mathrm{l}$ of sample buffer preheated to $100^{\circ} \mathrm{C}$. The digested products were analyzed in $8 \%$ polyacrylamide gels by either Coomassie Blue staining or Western blot with a purified polyclonal antibody raised against a peptide comprising amino acids 648-665 of GRK2 (Chuang et al., 1997) at a 1:40 dilution. After stripping of the nitrocellulose membrane, it was incubated with the polyclonal antibody anti-FP1, raised against the fusion protein containing amino acids 50 to 145 of bovine GRK2 (1:1500; see Murga et al., 1996). Western blots were developed using a chemiluminescent method (ECL; Roche Applied Science, Mannheim, Germany). For proteomic analysis, GRK2 proteolytic products were separated by SDS-polyacrylamide gel electrophoresis and transferred to Immobilon-P membranes (Millipore, Bedford, MA). The $\sim 74-\mathrm{kDa}$ band was subjected to Edman degradation and $\mathrm{N}$-terminal sequencing using an Applied Biosystems 473A pulse-liquid phase protein sequencer.

Immunoprecipitation and Western Blot Analysis. A construct comprising the entire N-terminal domain of GRK2 together with a histidine tag (His-GRK2 2-187) was described previously (Sallese et al., 2000). The C-terminal domain of GRK2 was subcloned by inserting the polymerase chain reaction-amplified coding sequence of GRK2 438-689 into a minigen construct generated in the pRK5 vector (kindly donated by Dr. S. Cotecchia, University of Lausanne, Switzerland) by NcoI-BclI cloning. The resulting minigen construct containing $3^{\prime}$ - and $5^{\prime}$-untranslated sequences was subcloned by $E c o$ RI-XbaI digestion into the pREP4 vector (Invitrogen). HEK 293 cells were transfected by the LipofectAMINE Plus method following the manufacturer's instructions. The expressed protein GRK2 438-689 was stabilized inside the cell in the presence of the N-terminal GRK2 2-187 protein. To achieve similar levels of expression in control and coexpression conditions, we needed to use $2 \mu \mathrm{g}$ of GRK2 2-187 plus $2 \mu \mathrm{g}$ of GRK2 $438-689$ or $0.5 \mu \mathrm{g}$ of a plasmid expressing enhanced green fluorescent protein plus $4.5 \mu \mathrm{g}$ of GRK2 438-689 in controls for a 6-cm dish. Transfected cells were allowed to grow for $48 \mathrm{~h}$ and then lysed in a buffer containing $50 \mathrm{mM}$ Tris-HCl, $\mathrm{pH} 7.5,1 \%$ Triton X-100, $5 \mathrm{mM} \mathrm{MgCl}_{2}$, and $250 \mathrm{mM} \mathrm{NaCl}$ completed with a cocktail of protease inhibitors. After clarifying the lysate by centrifugation, the supernatant was incubated with ProBond resin (Invitrogen, Carlsbad, CA) or an anti-histidine tag antibody (Sigma) for $60 \mathrm{~min}$. Complexes were precipitated by protein $\mathrm{A}$ addition in the second case, and washed $4 \times 10 \mathrm{ml}$ in ice-cold lysis buffer before resolving the protein precipitate in a $12 \%$ polyacrylamide gel. Western Blots were incubated with an anti-FP2 antibody (1:600, raised against the C-terminal region of GRK2; see Murga et al., 1996) or the 
anti-histidine antibody (1:1000; Sigma) and developed using a chemiluminescent method (ECL; Roche).

Structural Modeling of GRK2 Domains. Sequence searches were done using BlastP (WU-BLAST2 2.08) and HMMER 2.2g programs against a database of nonredundant protein sequences generated by the EBI-EMBL. Alignments, displayed with Belvu 2.9, were performed by ClustalW 1.82, T-COFFEE 1.32, and HMM programs; PFAM and HSSP alignments have been also considered. Bootstrap trees have been obtained by ClustalW and diplayed with Treetool 2.0.1. Modeling is derived from SwissModel and SwissPdbViewer resources. Evaluation of the models was performed with the Eval123D web server. Ribbon representation of models was done with Molscript and Raster3D. The catalytic domain of GRK2 (residues 172-509) has been modeled based on the Protein Data Bank coordinates of protein kinase A (about $30 \%$ sequence homology) in closed [1cdkA (Bossemeyer et al., 1993) and 1atpE (Zheng et al., 1993)] and open [1cmkE (Zheng et al., 1993)] conformations. Hanks classification of kinases (http://pkr.sdsc.edu/html/pk_classification/ pk_catalytic/pk_hanks_class.html) has also been considered to improve and validate the alignment. The RGS-like domain (residues 52-172) was modeled based on structural coordinates obtained from rat RGS4 [1agrH (Tesmer et al., 1997)], and human GAIP bound to $\mathrm{G} \alpha(1 \mathrm{cmzA})$ was also considered. The PH domain is directly derived from the NMR structure [1bak: the Pleckstrin domain of GRK2 (Fushman et al., 1998)]. For detailed links to software and related references therein, see Supplemental Material. Unless noted otherwise, all programs were applied with default parameters, and no further refinement was done to homology models.

Docking Analysis and Predicted Interactions. Hex 2.4 was the method used for the docking of GRK2 domains. First, open and closed conformations of the GRK2 kinase domain (preliminary models, residues 148-509) are set as receptors, whereas the RGS domain corresponds to the ligand. As expected from the p21 activated kinase 1 (PAK1) structure, residue 172 of both chains must be nearby in space, so the corresponding docking solution with minimal distance was selected as an initial reference. Then, RGS has been docked onto the closed kinase conformation (residues 172-509), focusing from the referred previous solution, and the four top-ranking solutions were selected. Afterward, the first docking solution of RGS complexed to the closed kinase was set as the receptor molecule and the $\mathrm{PH}$ domain as a ligand. Ten first solutions were retained, and the first one is the proposed docking model for the three domains of GRK2.

Tree-determinants were computed using SequenceSpace v1.0 (Casari et al., 1995). SequenceSpace provides six-dimensional vectors for each protein and each residue [see Fig. A5b in Supplemental Material]. The position of the GRK2 or PAK1 vector was considered the reference point (arctan of second and third dimensions). Then, residual vectors have been translated considering this reference as the new origin of coordinates; the distances of all residual vectors to this origin were computed (only considering second and third dimensions). Therefore, the most representative tree-determinant residues have null distances, whereas other residues have greater ones. Residues were counted using these criteria and grouped for different distance ranges; cumulative observations for each range were plotted (using different cut-off points for PAK1 kinase residues and $\leq 5 \AA$ for GRK2 kinase residues). Plotting graphics were done with Xmgrace 5.1.6.

\section{Results}

To achieve the regulation of the enzymatic activity of GRK2, different intracellular modulators such as $\mathrm{PIP}_{2}, \mathrm{G} \beta \gamma$, and activated receptors make use of its capability to interact with $\mathrm{N}$ - or C-terminal domains in the kinase. We thus hypothesized that those particular domains may play a role in controlling GRK2 activity. Consequently, we studied GRK2mediated phosphorylation of the prototypic substrate rho- dopsin in the presence or absence of purified $\mathrm{N}$ - or C-terminal domains of GRK2 expressed as fusion proteins (called FP1 and FP2, respectively, for "fusion protein"). It is important to mention here that these polypeptides behave as independent, fully functional domains as far as its binding to other proteins is concerned (Murga et al., 1996). As shown in Fig. 1A, FP1 (amino acids 50 to 145) expands most of the N-terminal region in GRK2, which contains a region of homology to RGS proteins (Sallese et al., 2000), whereas FP2 corresponds to the complete C-terminal domain (residues 436 to 689 ). In the presence of any of those polypeptides, the activity of recombinant GRK2 was increased by $\sim 2$ fold (Fig. 1B). The extent of this activation is similar to that described for other known regulators of GRK2, such as phospholipids, mastoparan, receptor peptides, and PKC- or Src-mediated phosphorylation (Chuang et al., 1995; DebBurman et al., 1995; Sarnago et al., 1999; Haga et al., 2002). Interestingly, a synthetic peptide corresponding to amino acids 643 to 673 in the $\mathrm{C}$ terminus of GRK2 exerts a potent stimulatory effect on the basal activity of the kinase, comparable with that of FP2 (Fig. 1B). In sum, we can conclude that polypeptides corresponding to domains pertaining to GRK2 are able in vitro to alter the enzymatic activity of this kinase toward rhodopsin.

We next investigated whether the effects observed in the presence of intrinsic domains of the kinase could be mediated through mechanisms similar to those observed with potent activators of GRK2, such as G $\beta \gamma$ subunits. As shown in Fig. $2 \mathrm{~A}$, the strong activation obtained with $80 \mathrm{nM}$ purified $\mathrm{G} \beta \gamma$ subunits cannot be further increased in the presence of FP1 or FP2. By using different doses of G $\beta \gamma$, we observed that as G $\beta \gamma$ concentration increases, the stimulatory effect of FP1 is reduced (Fig. 2B). Thus, the effects of G $\beta \gamma$ and FP1 do not seem to potentiate each other; i.e., both regulators seem to be acting through similar mechanisms/domains. Conversely, the activation exerted by the simultaneous addition of FP1 and FP2 is stronger than the activation seen with any of these polypeptides used alone (Fig. 2C), thus suggesting that they may modulate the catalytic activity of GRK2 by independent means.

Although synthetic peptides or other soluble proteins such as casein are poor substrates of GRK2 compared with activated receptor (Onorato et al., 1995), they still have been proven to be valuable tools to quantify the phosphorylation reaction itself, bypassing potential indirect effects caused by substrate-recognition efficacy or titration of regulatory proteins present in purified receptor preparations. We thus analyzed GRK2 activity, this time using a soluble peptide as a substrate (Onorato et al., 1995). As can be seen in Fig. 3, GRK2 kinase activity toward this synthetic peptide was increased by 2 - to 2.6 -fold in the presence of FP1, FP2, or GRK2 643-673, which rules out possible effects of these polypeptides caused by competition with GRK2 itself for components present in the rhodopsin preparation. As reported previously (Haga et al., 1994), the presence of $\mathrm{G} \beta \gamma$ subunits in this assay promoted a modest although reproducible increase in peptide phosphorylation (Fig. 3). To gain a deeper mechanistic understanding on how the $\mathrm{N}$ - and C-terminal polypeptides could change the kinase activity of GRK2, we performed classic kinetic measurements using different doses of both modulators (FP1 and the C-terminal peptide) using rhodopsin as a substrate. This set of experiments suggested that the stimulatory effect of FP1 was biphasic, peaking at FP1 con- 
centrations of $1 \mu \mathrm{M}$ and significantly decreasing at higher concentrations (Fig. 4A). They also revealed that FP1 enhances the catalytic activity of GRK2 by increasing its $V_{\max }$ 2- to 3-fold without a significant effect on the $K_{\mathrm{m}}$ of the reaction (Fig. 4B). This biphasic pattern of modulation suggested the existence of multiple binding sites of different affinity for FP1 with opposing effects on GRK2 activity (see Discussion).

A similar dose dependence could be observed when using C-terminal domains of the kinase. In fact, when increasing concentrations of GRK2 643-673 were preincubated with recombinant kinase, the phosphorylation of rhodopsin was stimulated; this effect peaked at concentrations of peptide of $3 \mu \mathrm{M}$ (Fig. 5A). Higher concentrations progressively promoted a decrease in kinase activity, with almost complete inhibition of rhodopsin phosphorylation at concentrations of 50 to $100 \mu \mathrm{M}$. The latter effect can be explained by previous results showing that this peptide, which corresponds to the minimum G $\beta \gamma$ binding domain of GRK2 (Koch et al., 1993), is able to compete with native GRK2 for binding to endogenous $\mathrm{G} \beta \gamma$ present in the GPCR preparation (Koch et al., 1993; Murga et al., 1996). Interestingly, when casein was used as a substrate, this biphasic effect was not observed: the stimulation was apparent even at very high doses (Fig. 5B) and

A
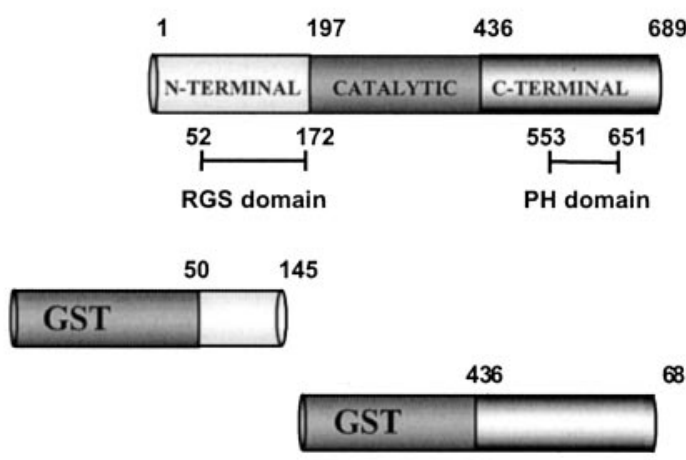

GRK2

FP1

FP2
B
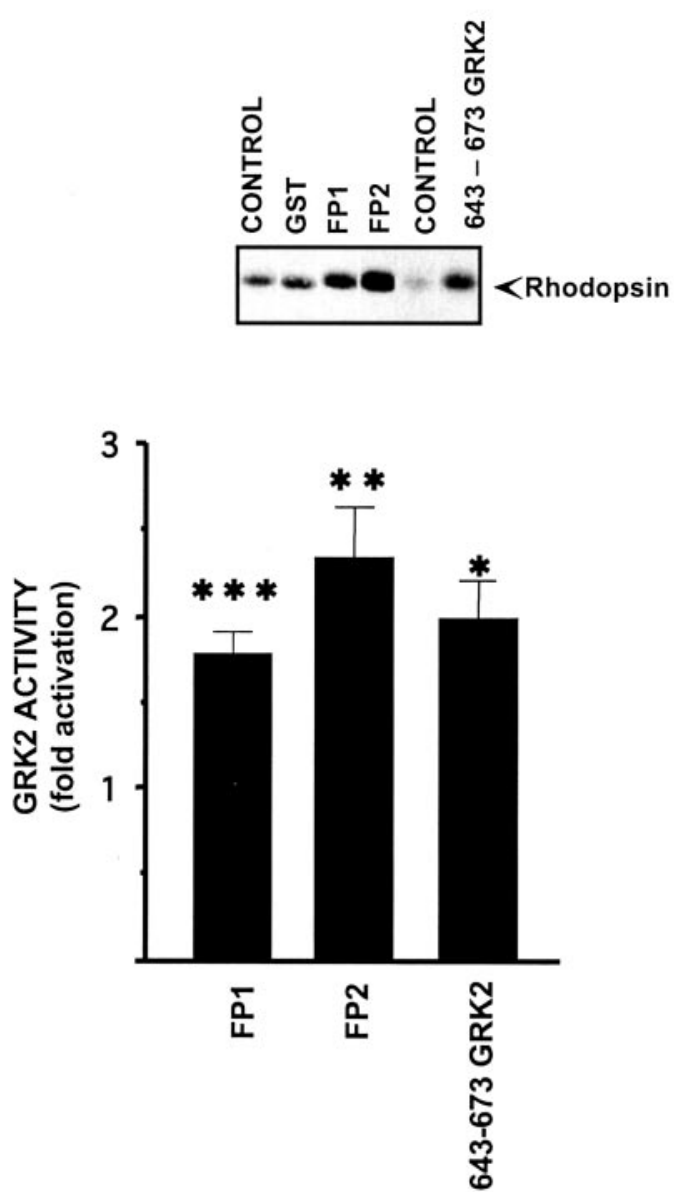

Fig. 1. Effect of GST-GRK2 fusion proteins and the synthetic peptide $643-673$ on kinase activity toward rhodopsin. A, domain structure of bovine GRK2 indicating the regions from which GST-fusion proteins containing amino acids 50-145 (FP1) and 437-689 (FP2) were derived. The proposed locations of the Pleckstrin homology domain (PH) and the RGS domain are also indicated. B, recombinant GRK2 (10 $\mathrm{nM}$ ) was preincubated alone or in the presence of fusion proteins $(3 \mu \mathrm{M})$ or a peptide belonging to the $\beta \gamma$-binding domain of bovine GRK2 (residues 643$673,5 \mu \mathrm{M})$. Rhodopsin phosphorylation was performed and quantified as detailed under Materials and Methods. Data are referred to control conditions (in the presence of $5 \mu \mathrm{M}$ GST for fusion proteins or an unrelated peptide for GRK2 643-673) and are means \pm S.E.M. of five to seven experiments. A representative autoradiograph is shown in the inset. *, $p<0.05$; **, $p<0.005$;**, $p<0.0005$ relative to controls with GST for fusion proteins or vehicle for the peptide. 
maintained throughout a wide range of casein concentrations (Fig. 5C). Kinetic analysis revealed that GRK2 643-673 influences the $V_{\max }$ of the kinase reaction $(389 \pm 69 \mathrm{fmol}$ of phosphate/min compared with control values of $168 \pm 30$ fmol of phosphate/min, $p<0.05$ ) without significantly changing the $K_{\mathrm{m}}$. The observed increase in the $V_{\max }$ of the enzymatic reaction, suggests that these domains promote the induction of conformational changes that result in a more efficient catalysis.

Therefore, we next studied whether the C-terminal peptide GRK2 643-673 could influence the kinase susceptibility to

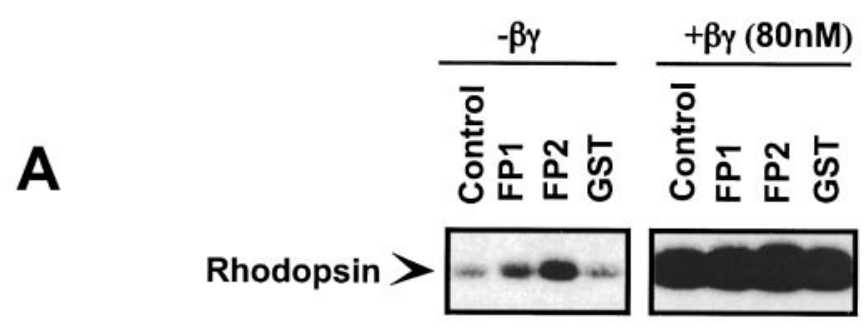

B

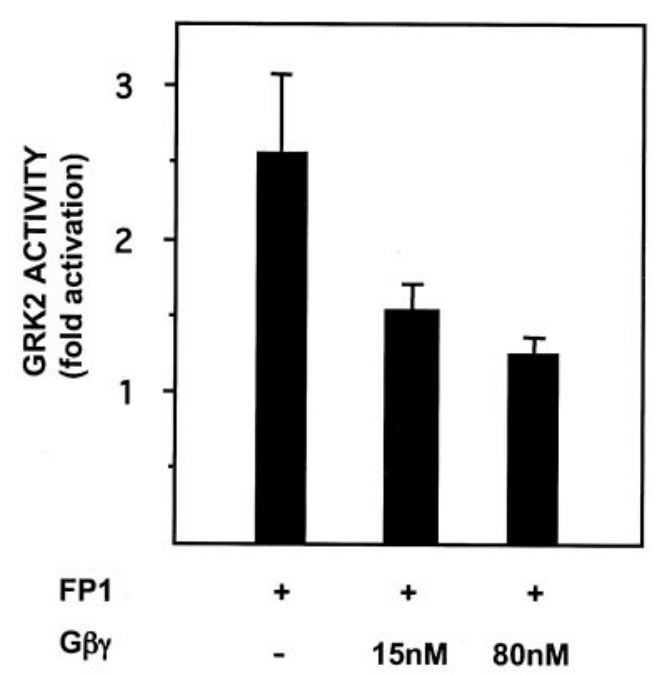

C

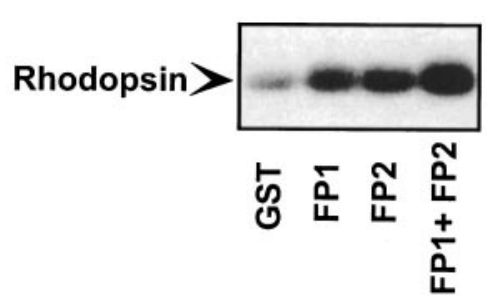

Fig. 2. Effect of GST-GRK2 fusion proteins on rhodopsin phosphorylation by GRK2 in the presence of other kinase activators. A, the kinase was incubated with fusion proteins $(1 \mu \mathrm{M})$ or GST as a control, in the presence or absence of $\mathrm{G}$ protein $\beta \gamma$ subunits $(80 \mathrm{nM})$. A rhodopsin phosphorylation assay was performed as described in Fig. 1B. An autoradiogram representative of three independent experiments is shown. B, recombinant GRK2 $(10 \mathrm{nM})$ was preincubated with FP1 $(1 \mu \mathrm{M})$ in the absence or presence of $\mathrm{G} \beta \gamma$ subunits ( $15 \mathrm{nM}$ and $80 \mathrm{nM}$ ) and used in a rhodopsin phosphorylation assay as described above. Data are referred to control conditions with GST $(1 \mu \mathrm{M})$ plus the corresponding amount of $\mathrm{G} \beta \gamma$ subunits. Means \pm S.E.M. obtained from at least three separate determinations are shown. $\mathrm{C}$, the phosphorylation reaction was performed and quantified as described previously by preincubating GRK2 $(10 \mathrm{nM})$ in the presence of the indicated fusion proteins $(1 \mu \mathrm{M})$. Results are representative of two independent experiments. proteolytic cleavage as an indicator of possible changes in GRK2 conformation. This experimental approach has already been used to demonstrate a direct interaction of phospholipids with GRK2 (Onorato et al., 1995). As observed in Fig. 6A, the partial proteolysis of purified recombinant GRK2 by trypsin renders a pattern of digested fragments in which the main species pertains to a band of $\sim 74 \mathrm{kDa}$. The presence of peptide 643-673 partially protects native GRK2 from this proteolytic cleavage, because some full-length GRK2 (80 $\mathrm{kDa}$ ) remains undigested in the presence of this peptide, and not when similar concentrations of scrambled or unrelated peptide sequences were used.

The proteolytic fragments obtained from recombinant GRK2 were analyzed by Western Blot using specific antibodies generated against N-terminal (anti-FP1 50-145) or Cterminal (anti-648-665 GRK2) domains in GRK2. Interestingly, the $\sim 74-\mathrm{kDa}$ fragment is clearly recognized by the antibody raised against the $\mathrm{C}$ terminus of the kinase (Fig. $6 \mathrm{~B})$, thus suggesting that the digestion by trypsin takes place at the $\mathrm{N}$ terminus of GRK2. We subjected this band to automated Edman degradation and identified two different proteolytic fragments that were not resolved in this type of gels. Sequence analysis indicated that the two trypsin cleavage sites were located at the $\mathrm{N}$ terminus of GRK2, specifically between residues K21/A22 and R27/A28 (Fig. 6C). However, the possibility that additional partial cleavage sites exist at the $\mathrm{C}$ terminus of the protein leading to similar fragments cannot be completely ruled out. The fact that the GRK2 C-terminal peptide protects from a tryptic digestion at the $\mathrm{N}$-terminal region of GRK2 strongly suggests that this Cterminal peptide directly interacts with or influences the conformation of, the $\mathrm{N}$ terminus of the kinase.

All these results pointed at the possibility that the different domains present in GRK2 are likely to be interacting

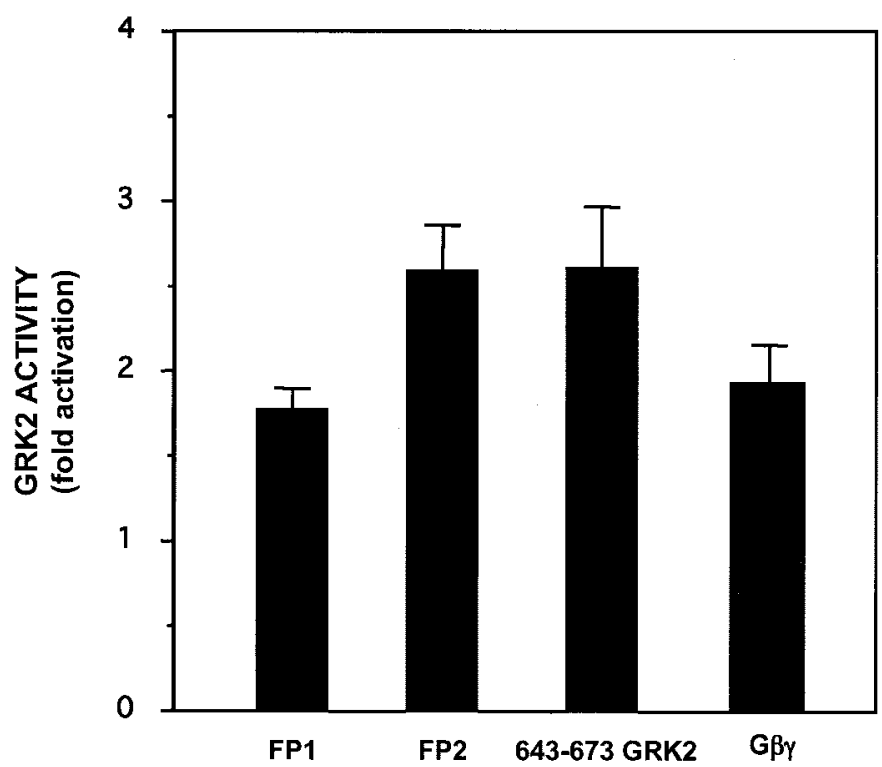

Fig. 3. Effect of GST-GRK2 fusion proteins and the synthetic peptide 643-673 on kinase activity toward a soluble peptide substrate. Recombinant GRK2 (25 nM) was preincubated for $15 \mathrm{~min}$ at $37^{\circ} \mathrm{C}$, alone or in the presence of fusion proteins $(5 \mu \mathrm{M})$ or the $643-673$ peptide $(5 \mu \mathrm{M})$. Control conditions are set in the presence of $5 \mu \mathrm{M}$ GST. Data are means \pm S.E.M. of three experiments performed in triplicate. Similar experiments were performed in the presence of $80 \mathrm{nM}$ G $\beta \gamma$ subunits. Data represent the mean \pm S.E.M. of 6 experiments. 
with one another. Results were also compatible with the importance of the association/dissociation of these domains for the regulation of the catalytic activity of GRK2. With the aim of exploring the feasibility of these intramolecular interactions, we used molecular modeling techniques. First, a model structure of each of the key domains of the kinase was obtained, namely the RGS-like, the catalytic, and the $\mathrm{PH}$ domain, based on available NMR or crystallographic coordinates for GRK2 or related proteins (see Materials and Methods and Figs. A1 to A4 in the Supplemental Material). Next, a set of alternative models for the interactions among the three domains was elaborated based on plausible physical docking solutions (see Materials and Methods). To discriminate among these different docking solutions, we took into consideration our own experimental results as well as the information obtained from the literature. Altogether, we propose in Fig. 7 a model in which the RGS and $\mathrm{PH}$ domains would be located on top of the kinase catalytic cleft. This three-dimensional configuration represents an inactive "basal" conformation in which the RGS domain would somehow occlude the catalytic cavity, thus impairing the entry of substrates into the active site. This conformation shows a certain degree of structural similarity with the spatial arrangement described for the autoregulatory p21 binding domain in the kinase PAK1. By sitting on this position, this regulatory

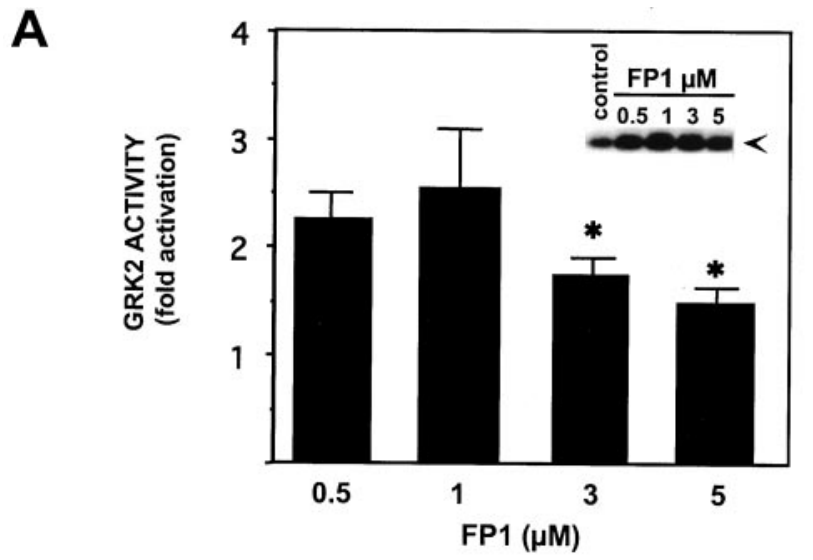

B

\begin{tabular}{ccc}
\multicolumn{2}{c}{$\begin{array}{c}\text { Rhodopsin phosphorylation kinetics } \\
\text { in the presence or absence of FP1 }\end{array}$} \\
\hline$K m$ & $V \max$ \\
\hline$\mu \mathrm{M}$ & $\mathrm{pmol} \mathrm{Pi} /(\mathrm{min} \cdot \mathrm{mg})$ \\
$\mathrm{GST}$ & $0.78 \pm 0.16$ & $2.77 \pm 0.6$ \\
$\mathrm{FP} 1$ & $1.29 \pm 0.35$ & $6.84 \pm 1.53$ \\
\hline
\end{tabular}

Fig. 4. Analysis of the effect of an N-terminal GST-GRK2 fusion protein (FP1) on GRK2 activity toward rhodopsin. A, recombinant GRK2 (10 nM) was preincubated in the presence of FP1 or the same concentrations of GST as a control and used in a rhodopsin phosphorylation reaction as described above. Data are referred to the basal values obtained in control conditions with GST and are means \pm S.E.M. of 3 to 11 independent experiments. ${ }^{*}, p<0.05$ with respect to values obtained with FP1 $1 \mu \mathrm{M}$. $\mathrm{B}$, the kinetic parameters of phosphorylation were determined in the presence of FP1 $(3 \mu \mathrm{M})$ and varying amounts of rhodopsin. After the phosphorylation reaction, the bands were excised and counted, and kinetic parameters determined by linear regression analysis of reciprocal plots. $K_{\mathrm{m}}$ and $V_{\max }$ values are means \pm S.E.M. of three different experiments performed in duplicate. domain helps maintain the kinase PAK1 in an inhibited conformation (Lei et al., 2000). Interestingly, the RGS domain of GRK2 shows some degree of structural homology with the p21 binding domain of PAK1. Moreover, described sites of interaction of GRK2 with other proteins, such as G $\beta \gamma$, and phospholipid binding sites at the $\mathrm{PH}$ domain (Carman et al., 2000), and the G $\alpha$ at the RGS domain (as described in the structure of $1 \mathrm{cmzA}$; see Supplemental Material), would remain accessible in the proposed docking model (Fig. 7C).

This interaction model, based on physical and experimental information, has been independently confirmed with the analysis of the corresponding sequence families. The SequenceSpace method was used for predicting functionally representative residues (tree determinants), taking as an input the alignments of the GRK2 sequence families (see Materials and Methods and Supplemental Material). Additional validation was carried out by applying the same methods to the PAK1 kinase family, for which the structure of the complex has been described previously (see Fig. A5 of the Supplemental Material). As can be seen in both cases, the interfaces between domains contain a significant concentration of tree-determinant residues. Other tree determinants sit outside the proposed interfaces, mostly in regions that interact with other effectors (e.g., G $\alpha$ for RGS, or phospholipids and $\mathrm{G} \beta \gamma$ for $\mathrm{PH}$ ). In Fig. 8, the most representative tree-determinants for the three domains of GRK2 are displayed, and residues $\leq 5 \AA$ from neighboring chains are marked. We further assessed whether the distribution of tree-determinant residues was not only qualitatively but also quantitatively favorable in the proposed docking solution compared with alternative ones by using two different meth-
A

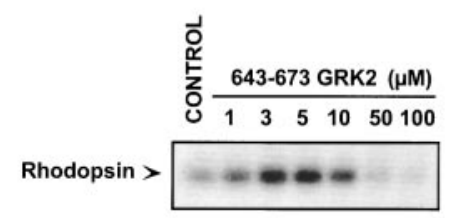

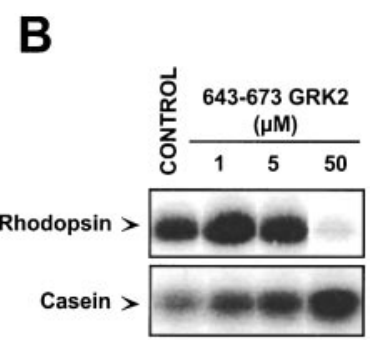
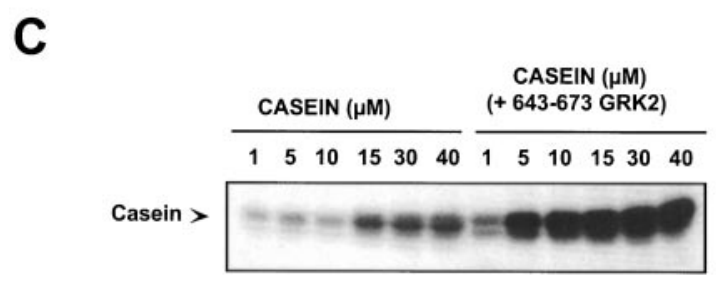

Fig. 5. Analysis of the effects of peptide 643-673 on GRK2 activity toward rhodopsin and the soluble substrate casein. A, recombinant GRK2 $(10 \mathrm{nM})$ was preincubated alone or in the presence of the peptide containing the $\beta \gamma$-binding domain of bovine GRK2 at the concentrations depicted in the figure. The effect of peptide addition on GRK2 activity was assessed by the rhodopsin phosphorylation assay. B, recombinant GRK2 (10 $\mathrm{nM}$ for rhodopsin or $25 \mathrm{nM}$ for casein experiments, respectively) was preincubated with or without the $643-673$ peptide (1, 5, and $50 \mu \mathrm{M})$, and its activity was determined by using the assays described under Materials and Methods. The phosphorylated substrate was resolved by SDSPAGE followed by autoradiography. C, recombinant GRK2 was preincubated alone or in the presence of the $643-673$ peptide $(50 \mu \mathrm{M})$ and its activity toward different concentrations of casein assayed as described above. All autoradiographs shown are representative of three independent assays. 
ods. In a first approach, we mapped the most representative tree-determinant residues onto each docking solution (Fig. A5, Supplemental Material). Our proposed docking model contains 16 residues at $5 \AA$ or less of the RGS and PH domains of the total 29 tree determinants in the kinase domain, whereas the alternatives contain only between 9 and 13 residues near the bound domains. A second method is based on the analysis of the composition of the set of tree-determinant residues. Again in this case, if the configuration of the proposed docking model is considered, the set of tree determinants is clearly enriched on residues near the interdomain interfaces (Fig. A6, Supplemental Material). Therefore, both analyses of the SequenceSpace results support the model proposed by the docking method as the one that better fits the expected distribution of tree-determinant residues in the interdomain binding interfaces.

In search of biochemical evidence that further corroborates the occurrence of intramolecular interactions among GRK2 domains, we used a histidine-tagged construct that expands the complete $\mathrm{N}$-terminal region of GRK2 [amino acids 2-187 (Sallese et al., 2000)] and a polypeptide that includes the
GRK2 C-terminal domain (GRK2 438-689). Both constructs were expressed in HEK 293 cells and either a highly specific $\mathrm{Ni}^{2+}$ resin or monoclonal anti-histidine tag antibodies were used to pull down the N-terminal portion of GRK2. These approaches led to the specific coprecipitation of the C-terminal domain of GRK2, as recognized by Western Blot analysis (Fig. 9), only when the N-terminal segment was coexpressed. This result biochemically establish that an interaction between the $\mathrm{N}$ - and C-terminal domains of GRK2 is in fact taking place inside the cell.

\section{Discussion}

In the present study, we show that fusion proteins and synthetic peptides encompassing different GRK2 regions modulate kinase activity toward several substrates. These data indicate that intramolecular interactions could play a role in regulating GRK2 and suggest a model for GRK2 activation and translocation based on changes in proteinprotein interactions in both $\mathrm{N}$ - and $\mathrm{C}$-terminal domains of the kinase.

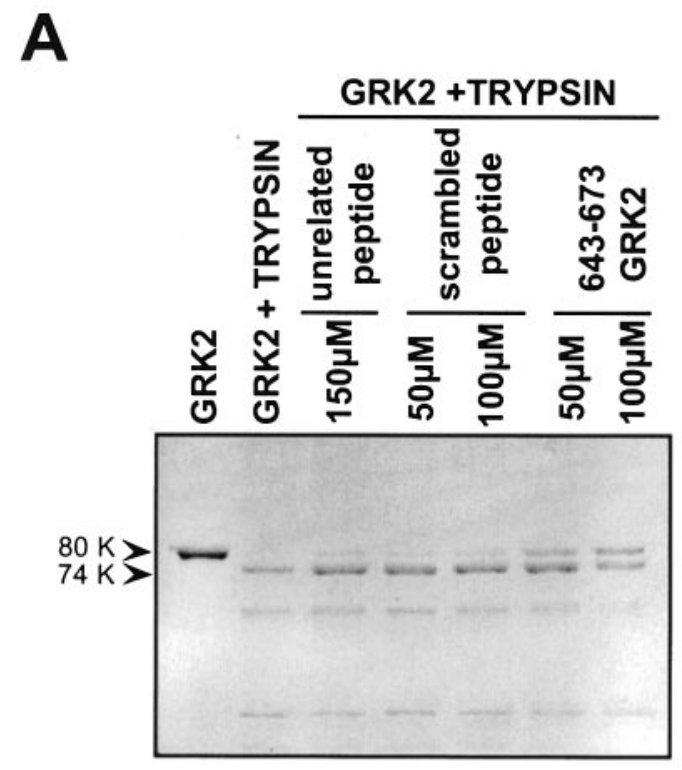

B

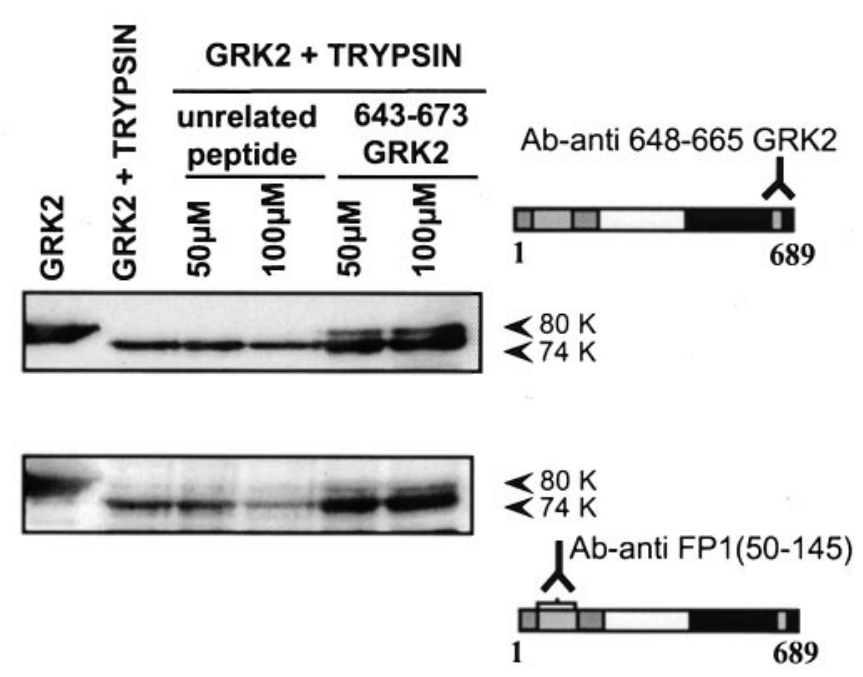

C

FP1

643-673

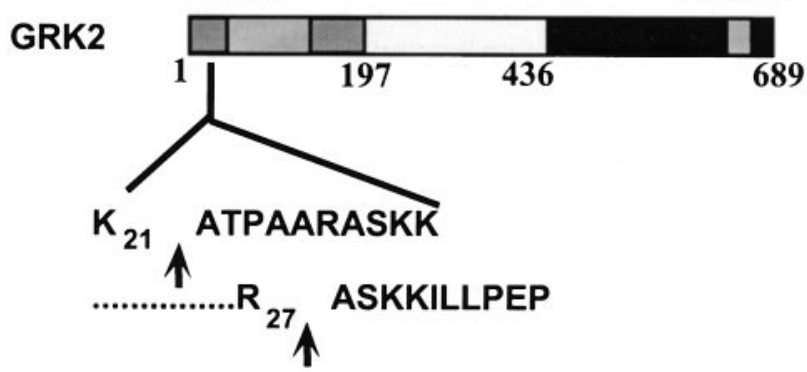

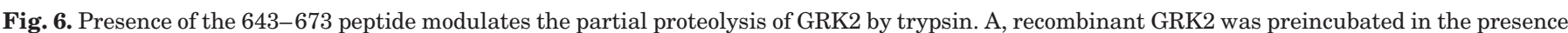

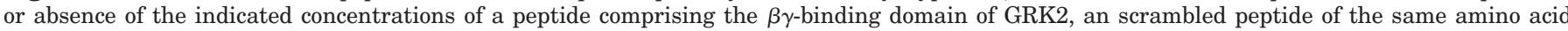

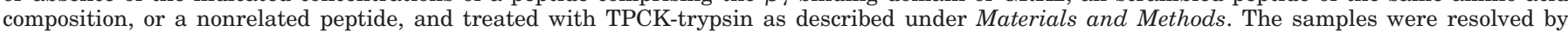

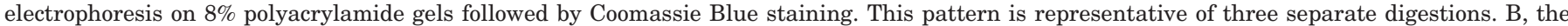

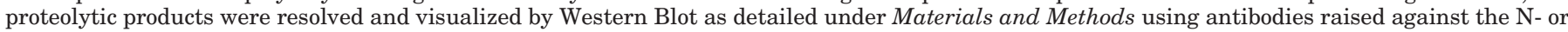

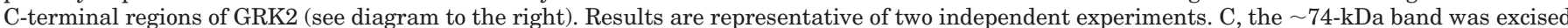

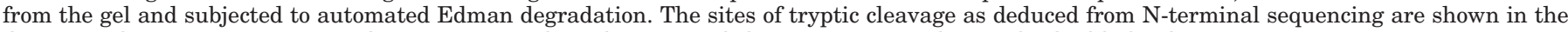
diagram. The segments corresponding to FP1, catalytic domain, and the 643-673 peptide are also highlighted. 
Our results put forward several interesting features of GRK2 modulation by intrinsic domains based on both enzymatic and biochemical data. First, the range of stimulation of GRK2 activity by its domains (2- to 3-fold) is similar to that reported for other kinase modulators, such as several lipids (DebBurman et al., 1995; Onorato et al., 1995), Src- or PKCmediated phosphorylation (Chuang et al., 1995; Sarnago et al., 1999), and also mastoparan and certain loops of GPCR (Haga et al., 2002). Second, the fact that intrinsic domains promote an increased GRK2 activity toward either rhodopsin
A

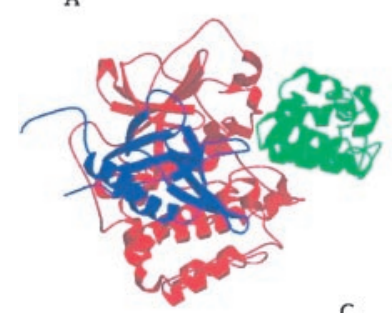

B

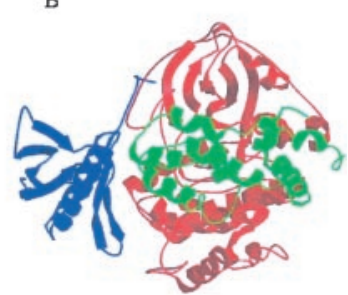

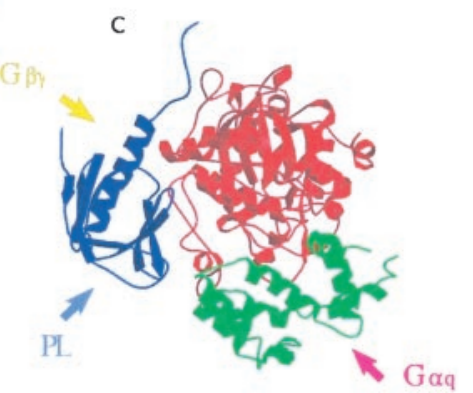

Fig. 7. Three-dimensional docking model for GRK2 domains. A, standard view of the catalytic domain (red) and the relative positions of the RGSlike (green) and $\mathrm{PH}$ (blue) domains. B, same as A, rotated $90^{\circ}$ on the vertical axis. C, alternate view; surfaces of previously described intermolecular interactions are displayed for $\mathrm{G} \beta \gamma$ subunits, G $\alpha \mathrm{q}$, and phospholipids (PL). See Materials and Methods for details.
A

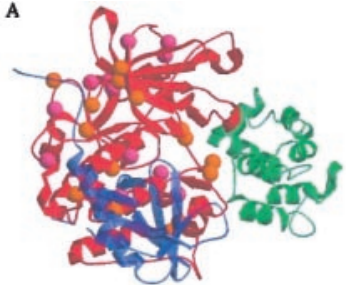

C

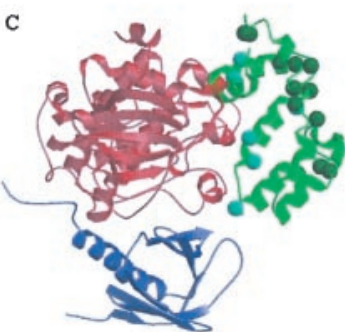

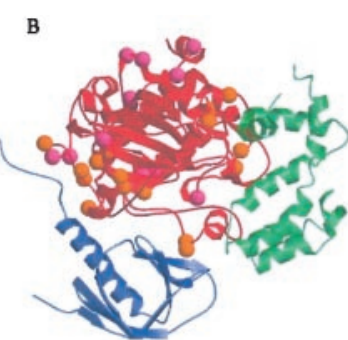

D

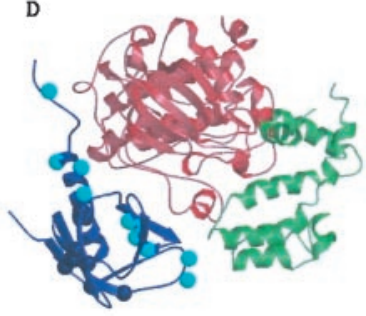

Fig. 8. Tree determinants and predicted intramolecular interactions. A and $\mathrm{B}$, a schematic representation of the kinase domain is shown in red; the tree determinant residues at $\leq 5 \AA$ to RGS or PH chains are depicted in orange and other possible intermolecular interactions are shown in pink. C, a model for the RGS domain of GRK2 is shown in green; those tree determinants at $5 \AA$ or less to kinase or PH chains are colored in light green; other possible intermolecular interactions are shown in dark green. $\mathrm{D}$, the $\mathrm{PH}$ domain model is depicted in blue; tree determinants sitting at $\leq 5 \AA$ to kinase or RGS chains are shown in light blue; other possible intermolecular interactions are shown in dark blue. See Materials and Methods and Supplemental Material for details. or soluble substrates indicates a direct effect on the catalytic mechanism, not mediated by interactions with membrane regulators or the activated receptor (Onorato et al., 1995; DebBurman et al., 1996). Third, we show here that when GRK2 is fully activated by G $\beta \gamma$ subunits, intrinsic domains are no longer able to interact with the kinase and/or to promote a more active conformation. Previous data also concluded that phosphatidylserine and G $\beta \gamma$ subunits activate GRK2 in a nonadditive way (DebBurman et al., 1996). The nonadditive nature of this type of kinase modulation suggests that both activators may act through similar mechanisms, either by sharing common sites of interaction with GRK2 or by promoting similar conformational changes leading to activation. Finally, the biphasic nature of GRK2 activation toward rhodopsin by either the $\mathrm{N}$-terminal fusion protein FP1 or the C-terminal peptide 647-673 suggests that at least two distinct processes are taking place. The stimulation observed at low concentrations would be a consequence of direct interaction between the exogenously added intrinsic domains and GRK2. At higher concentrations, the GSTGRK2 construct or the peptide 643-673 would compete with GRK2 for binding to the receptor and anchoring membrane components (G $\beta \gamma$ subunits), respectively (Koch et al., 1993; Pitcher et al., 1995). Because the N-terminal region of rhodopsin kinase has been implicated in interaction with the receptor (Palczewski et al., 1993), it is tempting to suggest that high concentrations of FP1 would be competing for in-

\section{Pull down: $\mathrm{Ni}^{2+}$ resin Anti-His}

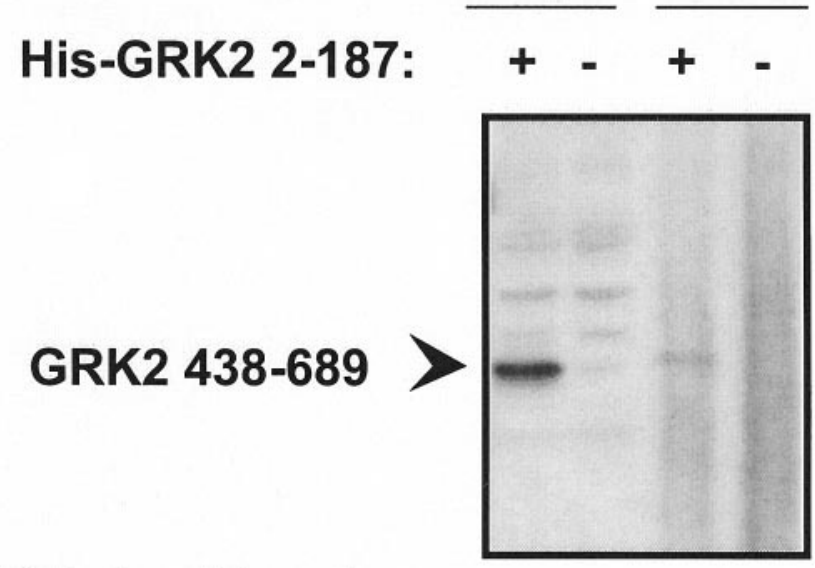

\section{Total cell lysates:}

\section{His-GRK2 2-187 \\ GRK2 438-689}
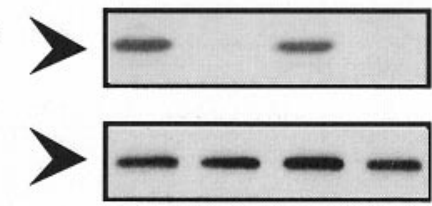

Fig. 9. Coprecipitation of the N- and C-terminal domains of GRK2. The N-terminal domain of GRK2 (residues 2-187) was expressed together with a minigen construct containing the C-terminal domain of GRK2 (GRK2 438-689) or enhanced green fluorescent protein as a control in HEK 293 cells. Transfected cells were lysed and centrifuged, and the supernatant was incubated with ProBond resin (Invitrogen) or an antihistidine antibody as indicated. After extensive washing, Western Blots were developed with an anti-GRK2 antibody (anti-FP2 1:600). Total cell lysates were assessed for the expression of GRK2 domains by using the anti-histidine antibody (1:1000) or the anti-FP2 antibody (bottom). 
B
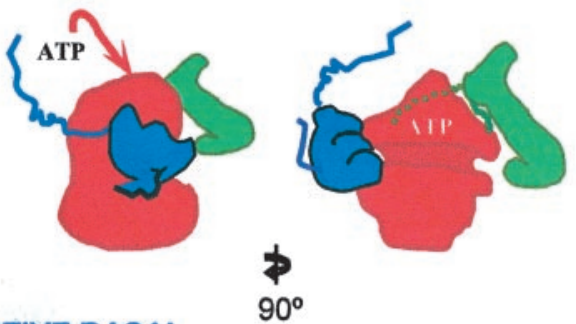

ACTIVE BASAL CONFORMATION

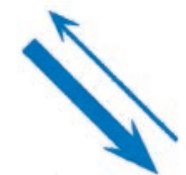

A

INACTIVE BASAL CONFORMATION
C

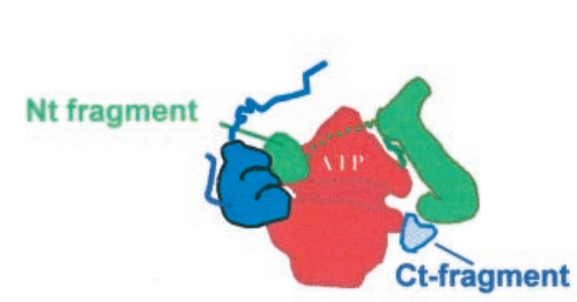

643-673 peptide

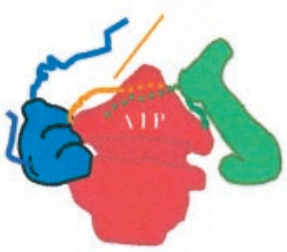

$\mathbf{N t}+\mathbf{C t}$

fragments

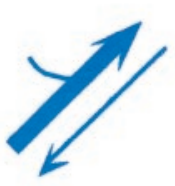

IN VITRO

ACTIVATION

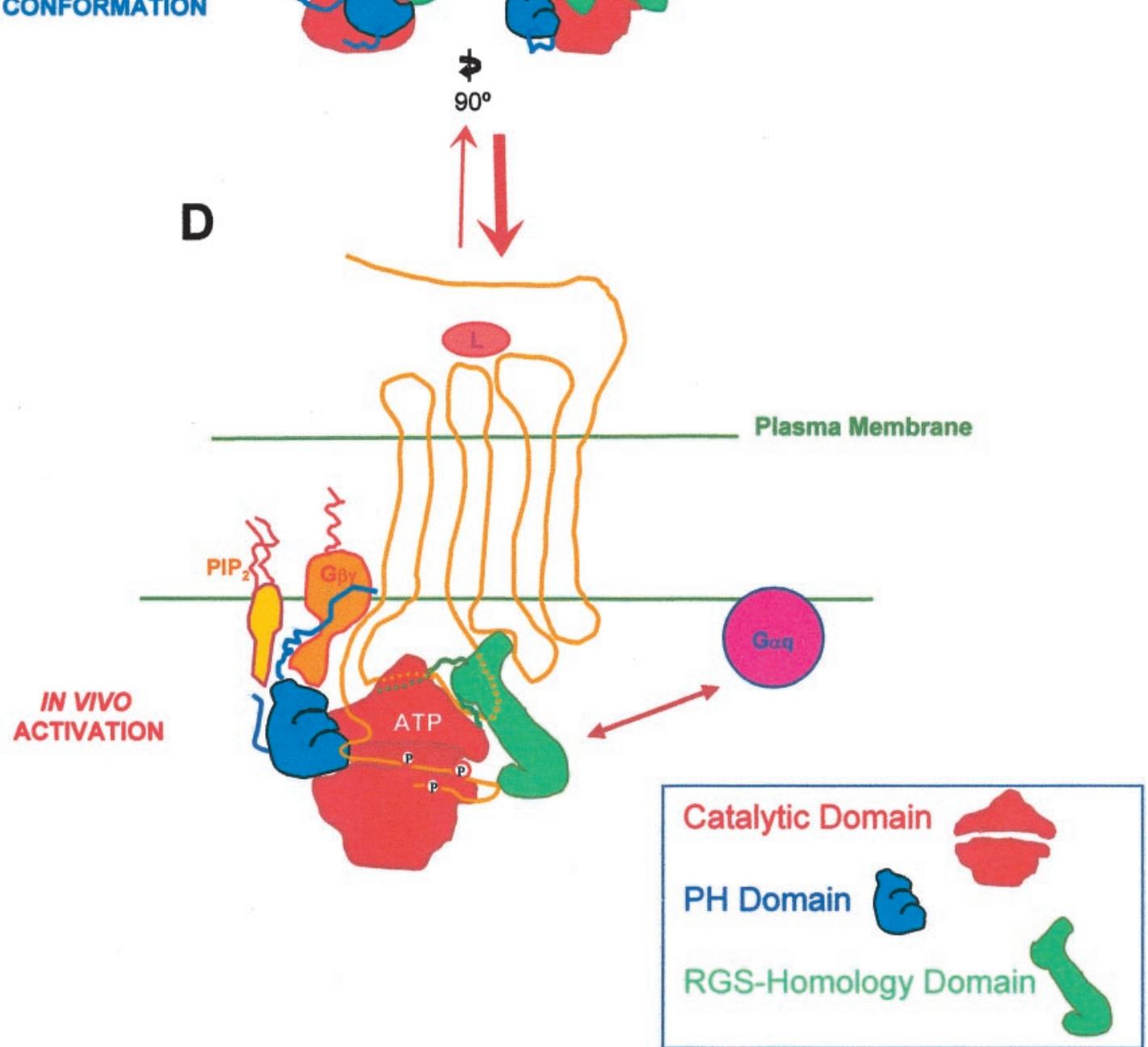

Fig. 10. Proposed model for GRK2 activation. In the absence of modulators, an equilibrium would exist between the active "open" (B) and inactive "closed" (A) conformation. It would be displaced toward the inactive conformation through stabilization by intramolecular interactions involving $\mathrm{N}$ and C-terminal domains of GRK2. C, in vitro, the substitution of such interactions by the addition of kinase fragments would allow the disruption of the constrained conformation and favor a more active state of GRK2. A similar mechanism would explain the in vitro effects on GRK2 activity of modulators (G $\beta \gamma$ subunits, phospholipids, receptor domains) able to bind to N- and C-terminal domains of GRK2. D, in vivo, the concerted interaction of such intracellular ligands with different GRK2 domains would simultaneously lead to the disruption of the inhibitory intramolecular associations and to the targeting of GRK2 to the plasma membrane, where the RGS domain would also be free to interact with G $\alpha$ q subunits. $\beta \gamma$, G protein $\beta \gamma$ subunits; circled P, putative GRK2 phosphorylation sites in the receptor. 
teraction of GRK2 with rhodopsin. Our results add to previous reports showing biphasic effects of several GRK2 modulators, such as mastoparan (Haga et al., 2002) or $\mathrm{PIP}_{2}$ (Pitcher et al., 1996), further suggesting that multiple interactions participate in the modulation of GRK2 activity and targeting.

An additional line of evidence indicates that the interaction of recombinant GRK2 with a C-terminal kinase peptide leads to a conformational state that is both more active and less sensitive to proteolytic cleavage. These results are further confirmed by coprecipitation experiments that demonstrate that the N- and C-terminal fragments of GRK2 associate inside the cell. The fact that the GRK2 643-673 peptide protects from $\mathrm{N}$-terminal cleavage sites (residues 21 and 27) strongly suggests that this peptide may directly interact with the most N-terminal segment of the kinase. This proposal not only explains the protection observed to partial proteolysis but also accommodates the fact that experiments based on coprecipitation of FP1 and FP2 were unsuccessful under many different conditions (S. Sarnago, C. Murga, and F. Mayor, unpublished results). If our hypothesis is correct, the most N-terminal portion of GRK2 would be involved in the interaction with the C-terminal fragment, and an efficient coprecipitation would be achieved only with a construct containing most of these first 50 amino acids (as is the case for GRK2 2-187) and not so much using FP1 (GRK2 50-145). It also provides an explanation for the fact that the GRK2 C-terminal protein was markedly stabilized inside the cell only in the presence of the N-terminal GRK2 2-187 protein (see Materials and Methods).

The stabilization of a basal, inactive state by intramolecular interactions has already been reported for other kinases such as PKC, and the prototypical regulation of Src kinases and Hck (Newton, 1995; Xu et al., 1997). More recently, other mechanisms of auto-regulation of protein kinases have been described, including autoinhibition by intrinsic domains for Brk (Qiu and Miller, 2002) or MEKK4 (Mita et al., 2002), existence of pseudosubstrate domains for GSK3 $\beta$ (Dajani et al., 2001), N-terminal cap models for c-Abl (Pluk et al., 2002), and inhibition in trans by homodimerization for PAK1 (Lei et al., 2000; Parrini et al., 2002). Examples of intrinsic peptides being able to modulate the enzymatic activity of protein kinases have been proven over time to represent key regulatory processes that control the biological function of these proteins. Such is the case for pseudosubstrate regulation of PKA, myosin light chain kinase subfamily, twitchin and titin, calmodulin kinase I, PAK, and Csk (Sondhi and Cole, 1999; Huse and Kuriyan, 2002). In addition, modulation of the catalytic activity by the intrinsic helix $\alpha \mathrm{C}$ is responsible for the allosteric regulation of cyclin-dependent kinase and Src families of proteins. Finally, autoinhibition by N-terminal fragments has been reported for the EphB2 receptor and the type I TGF $\beta$ receptor (Huse and Kuriyan, 2002). Although existing data are consistent with a similar intramolecular mechanism of regulation taking place in GRK2, the possibility that this modulation is accomplished by intermolecular rather than intramolecular interactions between GRK2 domains cannot be ruled out at this point. The possible existence of GRK2 dimers and/or the detailed map of intramolecular interactions would need further investigation and the elucidation of the crystal structure of GRK2.

The model depicted in Fig. 10 adequately explains the modulatory effects of GRK2 intrinsic domains on GRK2 activity. When phosphorylation assays are performed in the presence of either FP1 or FP2 (or peptide 643-673), the intramolecular interactions are possibly substituted by the "exogenous" domain, thus allowing for the disruption of the constrained conformation, resulting in a switch to a more active state. The in vivo effects on GRK2 catalytic activity of other ligands (phospholipids, G $\beta \gamma$ subunits, receptor domains) could also be explained in a similar way. The nonadditive nature of the stimulation by $\mathrm{G} \beta \gamma$ and intrinsic domains, as well as the occurrence of biphasic effects on GRK2 activity, are also consistent with this model. In vivo, the conformational rearrangement of GRK2 would be promoted by the concerted interaction of the kinase domains with the activated receptor, phospholipids, and $\mathrm{G} \beta \gamma$ subunits. It is worth noting that such activation mechanisms would simultaneously facilitate the disruption of inhibitory intramolecular interactions and the targeting of GRK2 to the plasma membrane. Therefore, this regulatory model intimately relates the process of GRK2 translocation to the plasma membrane with that of activation (DebBurman et al., 1996). It also helps explain how the RGS-like domain in GRK2 would be set free to interact with $\mathrm{G} \alpha$ subunits of $\mathrm{G}$ proteins at the plasma membrane, which is in accordance with a very recently published model (Sterne-Marr et al., 2003). It is noteworthy that interactions with the $\mathrm{N}$-terminal domain of the kinase often result in an inhibition of its catalytic activity, as is the case for binding to caveolin, calmodulin, actin, tubulin (see references in Penn et al., 2000), and a microsomal anchoring protein (Murga et al., 1996). On the other hand, C-terminal interactions frequently provoke an enhancement of the enzymatic activity, such as $\mathrm{G} \beta \gamma$ and $\mathrm{PIP}_{2}$ association. We suggest that $\mathrm{C}$-terminal modulators would cause a release of the constrained inactive structure, whereas most $\mathrm{N}$-terminal associations seem to facilitate a clamping effect further stabilizing the closed inactive conformation.

Traditionally, the exquisite specificity observed for GRK2 toward the activated form of seven transmembrane receptors as substrates has been regarded as a warrant that granted a possible lack of nonspecific phosphorylation reactions even in cellular contexts in which GRK2 seemed particularly abundant, such as in the brain and in hematopoietic cells. However, in view of recent reports describing a continuously growing number of new GRK2 substrates present in different intracellular locations (see references in Ruiz-Gomez et al., 2000), these assumptions should be readdressed. According to this new evidence, a molecular mechanism should exist to keep GRK2 protein inactive under a basal state and provide a means to stimulate its catalytic activity when required. The model proposed here provides such a mechanism of fine regulation even in compartments away from the classic plasma membrane-localized activation. We anticipate that this model will be experimentally challenged and we hope that it will be validated in the near future by long-awaited crystallographic structural data.

After this article was accepted, the crystallographic structure of the ATP free form of bovine G protein-coupled receptor kinase 2 in complex with $\mathrm{G} \beta \gamma$ subunits was reported (Lodowski et al., 2003) The structure is compatible with the type of regulatory intramolecular interactions described in the present article. A detailed comparison with the model of 
the domain organization for the ATP-free state of the kinase can be found at http://www.pdg.cnb.uam.es/GRK2/.

\section{Acknowledgments}

We thank Dr. A. Ruiz-Gómez for recombinant GRK2, Drs. J. L. Benovic and S. Cotecchia for experimental tools, and Drs. J. Vázquez and A. Marina for sequencing GRK2 proteolytic products.

\section{References}

Benovic JL, Onorato J, Lohse MJ, Dohlman HG, Staniszewski C, Caron MG, and Lefkowitz RJ (1990) Synthetic peptides of the hamster beta 2-adrenoceptor as substrates and inhibitors of the beta-adrenoceptor kinase. Br J Clin Pharmacol 30 Suppl 1:3S-12S.

Bossemeyer D, Engh RA, Kinzel V, Ponstingl H and Huber R (1993) Phosphotransferase and substrate binding mechanism of the cAMP-dependent protein kinase catalytic subunit from porcine heart as deduced from the $2.0 \mathrm{~A}$ structure of the complex with $\mathrm{Mn}^{2+}$ adenylyl imidodiphosphate and inhibitor peptide PKI(5-24). EMBO (Eur Mol Biol Organ) J 12:849-859.

Carman CV, Barak LS, Chen C, Liu-Chen LY, Onorato JJ, Kennedy SP, Caron MG, and Benovic JL (2000) Mutational analysis of G $\beta \gamma$ and phospholipid interaction with G protein-coupled receptor kinase 2. J Biol Chem 275:10443-10452.

Casari G, Sander C, and Valencia A (1995) A method to predict functional residues in proteins. Nat Struct Biol 2:171-178.

Chen CY, Dion SB, Kim CM, and Benovic JL (1993) $\beta$-Adrenergic receptor kinase. Agonist-dependent receptor binding promotes kinase activation. J Biol Chem 268:7825-7831.

Chuang TT, LeVine H 3rd, and De Blasi A (1995) Phosphorylation and activation of $\beta$-adrenergic receptor kinase by protein kinase C. J Biol Chem 270:18660-18665.

Chuang TT, Pompili E, Paolucci L, Sallese M, De Gioia L, Salmona M, and De Blasi A (1997) Identification of a short sequence highly divergent between betaadrenergic-receptor kinases 1 and 2 that determines the affinity of binding to betagamma subunits of heterotrimeric guanine-nucleotide-binding regulatory proteins. Eur J Biochem 245:533-540.

Dajani R, Fraser E, Roe SM, Young N, Good V, Dale TC, and Pearl LH (2001) Crystal structure of glycogen synthase kinase 3 beta: structural basis for phosphateprimed substrate specificity and autoinhibition. Cell 105:721-732.

DebBurman SK, Ptasienski J, Benovic JL, and Hosey MM (1996) G protein-coupled receptor kinase GRK2 is a phospholipid-dependent enzyme that can be conditionally activated by G protein $\beta \gamma$ subunits. J Biol Chem 271:22552-22562.

DebBurman SK, Ptasienski J, Boetticher E, Lomasney JW, Benovic JL, and Hosey MM (1995) Lipid-mediated regulation of G protein-coupled receptor kinases 2 and 3. J Biol Chem 270:5742-5747.

Fushman D, Najmabadi-Haske T, Cahill S, Zheng J, LeVine H, 3rd and Cowburn D (1998) The solution structure and dynamics of the pleckstrin homology domain of G protein-coupled receptor kinase 2 ( $\beta$-adrenergic receptor kinase 1$)$. A binding partner of G $\beta \gamma$ subunits. J Biol Chem 273:2835-2843.

Haga T, Haga K, Kameyama K, Tsuga H, and Yoshida N (2002) Regulation of G protein-coupled receptor kinase 2. Methods Enzymol 343:559-577.

Haga K, Kameyama K, and Haga T (1994) Synergistic activation of a G proteincoupled receptor kinase by $\mathrm{G}$ protein $\beta \gamma$ subunits and mastoparan or related peptides. J Biol Chem 269:12594-12599.

Huse M and Kuriyan J (2002) The conformational plasticity of protein kinases. Cell 109:275-282.

Koch WJ, Inglese J, Stone WC, and Lefkowitz RJ (1993) The binding site for the $\beta \gamma$ subunits of heterotrimeric $\mathrm{G}$ proteins on the $\beta$-adrenergic receptor kinase. $J$ Biol Chem 268:8256-8260

Lei M, Lu W, Meng W, Parrini MC, Eck MJ, Mayer BJ, and Harrison SC (2000) Structure of PAK1 in an autoinhibited conformation reveals a multistage activation switch. Cell 102:387-397.

Lodowski DT, Pitcher JA, Capel WD, Lefkowitz RJ, and Tesmer JJ (2003) Keeping G proteins at bay: a complex between $\mathrm{G}$ protein-coupled receptor kinase 2 and $\mathrm{G} \beta \gamma$. Science (Wash DC) 300:1256-1262

Mita H, Tsutsui J, Takekawa M, Witten EA, and Saito H (2002) Regulation of MTK1/MEKK4 kinase activity by its N-terminal autoinhibitory domain and GADD45 binding. Mol Cell Biol 22:4544-4555.

Murga C, Ruiz-Gomez A, Garcia-Higuera I, Kim CM, Benovic JL, and Mayor F Jr (1996) High affinity binding of $\beta$-adrenergic receptor kinase to microsomal mem- branes. Modulation of the activity of bound kinase by heterotrimeric G protein activation. J Biol Chem 271:985-994.

Naga Prasad SV, Barak LS, Rapacciuolo A, Caron MG, and Rockman HA (2001) Agonist-dependent recruitment of phosphoinositide 3-kinase to the membrane by $\beta$-adrenergic receptor kinase 1. A role in receptor sequestration. J Biol Chem 276:18953-18959.

Newton AC (1995) Protein kinase C: structure, function and regulation. J Biol Chem 270:28495-28498.

Onorato JJ, Gillis ME, Liu Y, Benovic JL, and Ruoho AE (1995) The $\beta$-adrenergic receptor kinase (GRK2) is regulated by phospholipids. J Biol Chem 270:2134621353.

Palczewski K, Buczylko J, Lebioda L, Crabb JW, and Polans AS (1993) Identification of the $\mathrm{N}$-terminal region in rhodopsin kinase involved in its interaction with rhodopsin. J Biol Chem 268:6004-6013.

Parrini MC, Lei M, Harrison SC, and Mayer BJ (2002) Pak1 kinase homodimers are autoinhibited in trans and dissociated upon activation by Cdc42 and Rac1. Mol Cell 9:73-83.

Penn RB, Pronin AN, and Benovic JL (2000) Regulation of G protein-coupled receptor kinases. Trends Cardiovasc Med 10:81-89.

Pierce KL, Premont RT, and Lefkowitz RJ (2002) Seven-transmembrane receptors. Nat Rev Mol Cell Biol 3:639-650.

Pitcher JA, Fredericks ZL, Stone WC, Premont RT, Stoffel RH, Koch WJ and Lefkowitz RJ (1996) Phosphatidylinositol 4, 5-bisphosphate (PIP2)-enhanced G protein-coupled receptor kinase (GRK) activity. Location, structure and regulation of the PIP2 binding site distinguishes the GRK subfamilies. J Biol Chem 271: 24907-24913.

Pitcher JA, Freedman NJ, and Lefkowitz RJ (1998) G protein-coupled receptor kinases. Annu Rev Biochem 67:653-692

Pitcher JA, Inglese J, Higgins JB, Arriza JL, Casey PJ, Kim C, Benovic JL, Kwatra MM, Caron MG, and Lefkowitz RJ (1992) Role of beta gamma subunits of G proteins in targeting the beta-adrenergic receptor kinase to membrane-bound receptors. Science (Wash DC) 257:1264-1267.

Pitcher JA, Touhara K, Payne ES, and Lefkowitz RJ (1995) Pleckstrin homology domain-mediated membrane association and activation of the $\beta$-adrenergic receptor kinase requires coordinate interaction with G $\beta \gamma$ subunits and lipid. $J$ Biol Chem 270:11707-11710.

Pluk H, Dorey K, and Superti-Furga G (2002) Autoinhibition of c-Abl. Cell 108:247259.

Qiu H and Miller WT (2002) Regulation of the nonreceptor tyrosine kinase Brk by autophosphorylation and by autoinhibition. J Biol Chem 277:34634-34641.

Ruiz-Gomez A, Humrich J, Murga C, Quitterer U, Lohse MJ, and Mayor F Jr (2000) Phosphorylation of phosducin and phosducin-like protein by G protein-coupled receptor kinase 2. J Biol Chem 275:29724-29730.

Sallese M, Mariggio S, D'Urbano E, Iacovelli L, and De Blasi A (2000) Selective regulation of Gq signaling by G protein-coupled receptor kinase 2: direct interaction of kinase N terminus with activated G $\alpha$ q. Mol Pharmacol 57:826-831.

Sarnago S, Elorza A, and Mayor F Jr (1999) Agonist-dependent phosphorylation of the G protein-coupled receptor kinase 2 (GRK2) by Src tyrosine kinase. J Biol Chem 274:34411-34416.

Sondhi D and Cole PA (1999) Domain interactions in protein tyrosine kinase Csk. Biochemistry 38:11147-11155.

Sterne-Marr R, Tesmer JJ, Day PW, Stracquatanio RP, Cilente JA, O'Connor KE, Pronin AN, Benovic JL, and Wedegaertner PB (2003) G protein-coupled receptor kinase $2 / \mathrm{G} \alpha \mathrm{q} / 11$ interaction. A novel surface on a regulator of $\mathrm{G}$ protein signaling homology domain for binding G $\alpha$ subunits. J Biol Chem 278:6050-6058.

Tesmer JJ, Berman DM, Gilman AG, and Sprang SR (1997) Structure of RGS4 bound to AlF4-activated G(i alpha1): stabilization of the transition state for GTP hydrolysis. Cell 89:251-261.

Xu W, Harrison SC, and Eck MJ (1997) Three-dimensional structure of the tyrosine kinase c-Src. Nature (Lond) 385:595-602.

Zheng J, Knighton DR, Xuong NH, Taylor SS, Sowadski JM, and Ten Eyck LF (1993) Crystal structures of the myristylated catalytic subunit of cAMP-dependent protein kinase reveal open and closed conformations. Protein Sci 2:1559-1573.

Address correspondence to: Dr. Federico Mayor, Jr., Centro de Biología Molecular "Severo Ochoa", Consejo Superior de Investigaciones CientíficasUniversidad Autónoma de Madrid, 28049 Madrid, Spain. E-mail: fmayor@cbm.uam.es 